Georgia State University

ScholarWorks @ Georgia State University

9-28-2018

\title{
Relationship Intentions, Race, and Gender: Student Differences in Condom Use During Hookups Involving Vaginal Sex
}

Wendasha Jenkins Hall

Jennifer Toller Erausquin

Tracy R. Nichols

Amanda E. Tanner

Follow this and additional works at: https://scholarworks.gsu.edu/ghpc_articles

\section{Recommended Citation}

Hall, Wendasha Jenkins; Erausquin, Jennifer Toller; Nichols, Tracy R.; and Tanner, Amanda E., "Relationship Intentions, Race, and Gender: Student Differences in Condom Use During Hookups Involving Vaginal Sex" (2018). GHPC Articles. 130.

https://scholarworks.gsu.edu/ghpc_articles/130

This Article is brought to you for free and open access by the Georgia Health Policy Center at ScholarWorks @ Georgia State University. It has been accepted for inclusion in GHPC Articles by an authorized administrator of ScholarWorks @ Georgia State University. For more information, please contact scholarworks@gsu.edu. 


\section{Relationship intentions, race, and gender: Student differences in condom use during hookups involving vaginal sex}

Wendasha Jenkins Hall, Jennifer Toller Erausquin, Tracy R. Nichols, Amanda E. Tanner \& Shelly Brown-Jeffy

To cite this article: Wendasha Jenkins Hall, Jennifer Toller Erausquin, Tracy R. Nichols, Amanda E. Tanner \& Shelly Brown-Jeffy (2018): Relationship intentions, race, and gender: Student differences in condom use during hookups involving vaginal sex, Journal of American College Health, DOI: $10.1080 / 07448481.2018 .1506788$

To link to this article: https://doi.org/10.1080/07448481.2018.1506788

Published online: 28 Sep 2018.

Submit your article to this journal ¿

山 Article views: 10

View Crossmark data ¿ 


\title{
Relationship intentions, race, and gender: Student differences in condom use during hookups involving vaginal sex
}

\author{
Wendasha Jenkins Hall, PhD ${ }^{a}$, Jennifer Toller Erausquin, PhD, MPH ${ }^{b}$, Tracy R. Nichols, PhD ${ }^{b}$, Amanda E. \\ Tanner, PhD, MPH ${ }^{\mathrm{b}}$, and Shelly Brown-Jeffy, $\mathrm{PhD}^{\mathrm{c}}$

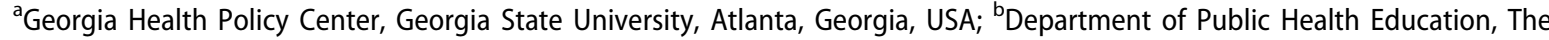 \\ University of North Carolina Greensboro, Greensboro, North Carolina, USA; 'Department of Sociology, The University of North Carolina \\ at Greensboro, Greensboro, North Carolina, USA
}

\begin{abstract}
Objective: To examine the relationship between race, gender, and pre-hookup relationship intentions and college students' participation in condomless vaginal sex. Participants: 3,315 Black and White college students who participated in the Online College Social Life Survey (OCSLS). Methods: Secondary data analysis of the OCSLS using Chi-square and multiple logistic regression analyses. Results: The model revealed that students who did not want a relationship with their hookup partners and students unsure of their relationship intentions were more likely to use condoms during their last vaginal hookup. Further, White and Female students were less likely to have used condoms during their last vaginal hookup. Conclusions: White and female students, as well as students desiring romantic relationships with hookup partners may be at risk for sexually transmitted infections (STIs) due to decreased condom use. However, more research is needed to explore the factors driving STI disparities facing Black students despite higher condom use.
\end{abstract}

\section{ARTICLE HISTORY}

Received 1 November 2017

Revised 5 June 2018

Accepted 26 July 2018

\section{KEYWORDS}

Race; gender; sexual health; relationships
Hookups - casual sexual encounters between individuals without the expectation of an ensuing dating or romantic relationship. ${ }^{1}$ - are a continued topic of interest among college and sexual health researchers. ${ }^{1-4}$ With estimates that $60 \%-80 \%$ of US college students report at least one hookup during their tenure, the potential sexual health consequences posed by hookups involving penetrative sex must be considered. ${ }^{1,2,5-8}$ The number of sexually transmitted infections (STIs) specifically attributable to hookups is unknown; yet young adults ages 15-24 account for $64.3 \%$ and $49.7 \%$ of all reported chlamydia and gonorrhea cases and in the US, respectively. ${ }^{9}$

Although not all hookups include penetrative behaviors, hookup events which include vaginal and anal sex may elevate the risk of STIs due to college students' inconsistent condom use. ${ }^{10,11}$ According to the American College Health Association's National College Health Assessment (ACHA-NCHA), ${ }^{12} 46 \%$ of students reported vaginal sex in the last 30 days, yet less than half of these students claimed to have always used a condom or used one most of the time during vaginal sex in the last 30 days. An event-level study of
824 students revealed that $53 \%(n=439)$ reported sexual intercourse during their last hookup. Of those reporting sexual intercourse, only $47 \% \quad(n=206)$ reported using a condom. ${ }^{10}$ In addition, the probability of unprotected sex during hookups increased from $7 \%$ to $16 \%$ among women, and from $6 \%$ to $15 \%$ among men between years 1 and 4 of college. ${ }^{13}$ Considering the ubiquity of hookups, the prevalence of inconsistent condom use among students, and risk of STI acquisition, an examination of condom use during vaginal sex hookups is necessary.

\section{Pre-hookup relationship intentions and condom use}

Several factors have been found to influence condom use among college students. Alcohol and substance abuse, feelings of invincibility, low risk perception, and perceived norms are all risk factors correlated with inconsistent condom use. ${ }^{14-17}$ Condom use is typically higher in casual sex relationships in comparison to romantic and monogamous relationships. ${ }^{13}$ However, 
very few studies discuss the influence of relationship intentions on condom use during hookups.

Hookups are often characterized as brief, commitment-free, "no strings attached" encounters. Consequently, it is assumed both participating parties have a mutual understanding of the expectations and outcomes of the sexual relationship. Yet, it is suggested some students may view hookups as potential avenues for establishing romantic partnerships. Garcia and Reiber's study ${ }^{18}$ of students' hookup motivations revealed that $54 \%$ cited emotional gratification, while $51 \%$ desired the initiation of a traditional romantic relationship; no gender differences were found. Another investigation found that $65 \%$ of women and $45.2 \%$ of men hoped their hookup encounter would progress into a committed relationship. ${ }^{19}$ Further, the study revealed that about $51 \%$ of women and $42 \%$ of men discussed the possibility of a committed relationship with their hookup partner. ${ }^{19}$

To our knowledge, there have been no investigations into the association between relationship intentions and condom use during hookups. But, condomless sex may be a method of securing a romantic partnership, particularly among women. ${ }^{20-23}$ Women typically outnumber men on US college campuses, ${ }^{24}$ and their large numbers often disadvantage them in the campus sexual marketplace - the campus social structures in which individuals search for a partner. ${ }^{2,25-28}$ Both men and women report similar rates of hooking up; however, the gender ratio disparity may afford men more power in partner selection and relationship formation. ${ }^{2,28}$ Women are more likely to prefer dating than the casual sex practice and those attending female-majority institutions who desire heterosexual dating arrangements may be less successful in their searches due to the short supply of suitable, potential partners. ${ }^{29} \mathrm{Men}$, on the other hand, may enjoy more dyadic power in their sexual and romantic partnerships due to the abundance of attractive alternatives within the sexual marketplace. $^{25,28,30,31}$ This phenomenon may lead some women to engage in non-monogamous relationships, settle for undesirable partners, and forgo condoms to edge out competition posed by other women. ${ }^{22,32-34}$ Accordingly, relationship intentions prior to hookups is an unexplored topic that requires further examination.

\section{Gender, race, and condom use}

Woman and Black citizens in the US face tremendous disparities in STI acquisition. ${ }^{9}$ Considering the current STI epidemic and sexual health disparities, researchers are also looking at the gender and racial differences that may exist in condom use during hookups. Overall, men and women report similar rates of hooking $\mathrm{up}^{35}$; however, women are at increased risk for STIs and HIV. ${ }^{14}$ Currently, women ages $15-24$ years old have higher rates of reported chlamydia cases, when compared to men within the same age group. ${ }^{9}$ Gonorrhea rates among women are highest among those aged 15-24, with 19 year old women having the highest rates among women in 2016. ${ }^{9}$ Penetrative hookups involving unprotected vaginal sex present a heightened risk to women as they are more susceptible to STIs and HIV due to the anatomy and physiology of the vagina, which makes viral and bacterial transmission more efficient. ${ }^{36-38}$ Among college women, this risk is exacerbated by inconsistent condom use.

Thirty-one percent of sexually active female college students always used condoms during vaginal sex in the last 30 days (compared to $54.5 \%$ of male students); however, the survey did not distinguish between sexual intercourse in monogamous versus casual relationships. ${ }^{12}$ A smaller study found no significant relationship between gender and condom use, yet of those participants reporting sexual intercourse in the past 3 months, more men (57\%) than women (43\%) reported condom use. ${ }^{39}$ This study also did not distinguish between condom use in monogamous versus casual relationships. Specific to hookups, a study of firstsemester college women found that $69 \%$ reported condom use during their most recent hookup. ${ }^{11}$ Another study of 10,275 students revealed that $67 \%$ of women used a condom the last time they had vaginal intercourse within hookup, compared to $74 \%$ of men. ${ }^{13}$ While some condom use studies do not distinguish between relationship status, evidence suggest condom use frequency among college women was found to decrease over time in both monogamous and casual sexual partnerships as partners become more familiar. ${ }^{40}$ More research involving gender differences in condom use in the context of hooking up is warranted.

In addition to gender, national STI surveillance data indicate stark racial disparities among young people of color; particularly, Black young adults are disproportionately overrepresented in the STI epidemic. The rate of reported chlamydia cases among Black young adults aged 15-24 years is $4,593.4$ cases per 100,000 , which is nearly 4.7 times the rate of their White counterparts. Regarding reported gonorrhea cases, rates among Black young adults aged 15-24 is 10.4 times that of whites $(1,487.3$ vs. 142.1 cases per 100,000). ${ }^{9}$ Several researchers have called for the inclusion of Black students in hookup studies. 
However, relatively little is known about this population's sexual behaviors and risk factors in the context of hookups and how they might differ from their White peers. ${ }^{3,28,33}$ This may be due to evidence suggesting that hookups are not prevalent among Black students and they are more likely to use condoms than White students. ${ }^{2,35,41,42}$ Despite this evidence, Black students should not be excluded from hookup research.

Several studies of Black students' sexual practices indicate inconsistent condom use. A CDC sponsored study focusing on HIV testing and prevention at seven historically Black colleges and universities (HBCUs) noted that $35.4 \%$ of respondents did not use a condom during last sexual intercourse. ${ }^{43}$ Another study of Black HBCU students found that $31 \%$ did not use a condom during their last sexual encounter. ${ }^{44}$ Further, $64 \%$ of students reporting two or more sexual partners in the previous 12 months did not use a condom during their last sexual encounter. El Bcheraoui et al.'s study ${ }^{45}$ of Black students attending 24 HBCUs corroborates these findings. The data revealed that $36.2 \%$ of students surveyed did not use condoms during their last sexual intercourse. Considering the adverse sexual health outcomes facing young Black adults and evidence detailing inconsistent condom use, further investigation into their sexual practices and risk behaviors in the context of hooking up is necessary.

\section{Current study}

Given the limitations of existing research on college sexual hookup behavior, this exploratory study examines the association between pre-hookup relationship intentions and condom use at last vaginal hookup. This study also examines racial and gender differences in condom use during last vaginal hookup. Understanding how relationship intentions, race, and gender influence condom use during hookups can inform racial- and gender-competent intervention and programing efforts that seek to reduce the incidence of STIs and promote sexual health among college populations.

\section{Methods}

This study involved secondary analysis of data from the Online College Social Life Survey (OCSLS). Conducted between 2005 and 2011, this 15-20 min survey was administered to 24,131 college students at 22 colleges and universities across the USA. ${ }^{46}$ A diverse set colleges and universities are included in the survey including large state universities, Ivy
League and elite private universities, regional and commuter universities, small liberal arts colleges, and one community college. All regions of the contiguous USA are represented in the survey. Survey participants were recruited in undergraduate courses - primarily in introductory sociology courses - using convenience sampling. Although recruitment was done largely in sociology courses, sociology majors represented 11\% of the sample population. ${ }^{46}$ Participation was voluntary and instructors offered course credit for those completing the survey or an alternative assignment for those choosing not to participate. Accordingly, the response rate was $99 \%-100 \%$ in most classes. ${ }^{46}$ The OCSLS captures data from a diverse cross-section of students regarding dating, hookups, relationships, and sexual attitudes and histories. The large sample size and diversity of participating schools renders the OCSLS the largest survey to explore hookup behaviors among college students across the USA.

\section{Inclusion criteria}

Given the focus on race, gender, and heterosexual relations among Black and White undergraduates, the analytic sample included students who met the following criteria: (1) self-reported racial identity of Black or White; (2) non-Hispanic ethnicity; (3) 18-24 years-old; (4) undergraduate status; (5) self-reported sexual orientation of heterosexual; (6) opposite sex encounter at last reported hookup; and (7) vaginal sex at last hookup.

\section{Measures}

\section{Demographics}

On the survey, students were asked to report the race and gender to which they identified. Dichotomous variables were created to specify male or female gender identification and Black or White racial identification.

\section{Pre-hookup relationship intentions}

Students were asked the following question about their last hookup partner: "Were you interested in having a romantic relationship with the person you hooked up with before you hooked up?" The response options for this item included: (1) "No, I wasn't at all interested," (2) "Possibly; I didn't really know yet," (3) "Maybe; it had some appeal," and (4) "Yes, I was definitely interested." This item was transformed to a categorical variable with three possible values representing no interest, unsure, and definite interest. 


\section{Condom use during last vaginal hookup}

This variable was created from two survey items. First, students were asked to identify all sexual behaviors that occurred during their last hookup encounter. Next, students were asked if they used a condom during their sexual encounter. A composite dichotomous variable was created to specify if the student reported condomless vaginal sex or condom-protected vaginal sex.

\section{Control variables}

In prior studies of young adults and college students, age, ${ }^{47}$ early initiation of sexual activity, ${ }^{48}$ undergraduate classification status, ${ }^{13}$ religiosity, ${ }^{49,50}$ fraternity/sorority membership, ${ }^{51}$ student athlete status, ${ }^{52}$ and student residence ${ }^{53}$ were all found to influence sexual behavior and condom use. Accordingly, these variables were controlled during data analysis.

\section{Analyses}

The Statistical Package for the Social Sciences 23.0 (SPSS 23) for Macintosh was used for data analysis. Descriptive univariate analyses were conducted to examine the distributions of the independent and dependent variables. Chi-square analyses were performed to examine the associations between the independent variables and the dependent variable. Chisquare analyses were also used to assess the associations of the independent variables with each of the control variables. Additionally, chi-square analyses were performed to examine the associations among the control variables and dependent variable.

Due to the nesting of students in schools, a multilevel model using random intercept logistic regression was tested to control for the influence of students' college or university on condom use at last vaginal hookup. The preliminary analysis revealed that the variability between schools was insignificant $(p=.32)$. Accordingly, single-level multiple logistic regression analyses were performed to assess whether pre-hookup relationship intentions, race and gender were associated with condom use at last vaginal hookup. A forward stepwise selection method was used so that only variables that significantly improved model fit and that were significantly associated with the dependent variable at the $p<.05$ level were retained in the final model.

\section{Results}

Table 1 summarizes the demographic characteristics of the Black and White students from the full OCSLS
Table 1. Comparison of OCSLS sample ${ }^{a}$ and analytic sample demographics.

\begin{tabular}{|c|c|c|c|c|}
\hline \multirow[b]{2}{*}{ OCSLS sample $(N=16,680)^{a}$} & \multicolumn{4}{|c|}{ Analytic sample $(N=3,315)$} \\
\hline & $N(\%)$ & Mean & $N(\%)$ & Mean \\
\hline \multicolumn{5}{|l|}{ Race } \\
\hline Black & $1,576(9.4)$ & & $267(8.1)$ & \\
\hline White & $15,104(90.6)$ & & $3,048(91.9)$ & \\
\hline \multicolumn{5}{|l|}{ Gender } \\
\hline Female & $11,395(68.3)$ & & $2,223(67.1)$ & \\
\hline Male & $5,285(31.7)$ & & $1,092(32.9)$ & \\
\hline Age & & 20.6 & & 20.14 \\
\hline 18 & $3,400(20.4)$ & & $488(14.7)$ & \\
\hline 19 & $4,490(26.9)$ & & $809(24.4)$ & \\
\hline 20 & $3,111(18.7)$ & & $696(21.0)$ & \\
\hline 21 & $2,584(15.5)$ & & $676(20.4)$ & \\
\hline 22 & $1,462(8.8)$ & & $431(13.0)$ & \\
\hline 23 & $460(2.8)$ & & $148(4.5)$ & \\
\hline 24 & $230(1.4)$ & & $67(2.0)$ & \\
\hline 25 & $907(5.4)$ & & $\mathrm{N} / \mathrm{A}$ & \\
\hline Unreported & $36(.2)$ & & $\mathrm{N} / \mathrm{A}$ & \\
\hline \multicolumn{5}{|l|}{ Class standing } \\
\hline Freshman (first year) & $5,864(35.2)$ & & $881(26.6)$ & \\
\hline Sophomore (second year) & $3,901(23.4)$ & & $776(23.4)$ & \\
\hline Junior (third year) & $3,229(19.4)$ & & $750(22.6)$ & \\
\hline Senior ( $4^{\text {th }}$ Year) & $2,795(16.8)$ & & $736(22.2)$ & \\
\hline $5^{\text {th }}$ year or higher & $693(4.2)$ & & $172(5.2)$ & \\
\hline Graduate & $168(1.0)$ & & N/A & \\
\hline Unreported & $30(0.2)$ & & $\mathrm{N} / \mathrm{A}$ & \\
\hline
\end{tabular}

${ }^{a}$ Only includes Black and White students from OCSLS sample.

Abbreviations: N/A, not applicable; OCSLS, Online College Social Life Survey.

sample and the analytic sample of the current study. The final analytic sample consisted of 3,315 undergraduate students. Like the OCSLS sample, most students were women $(67.1 \%)$ and White $(91.9 \%)$. The mean age was 20.14 years $(S D=1.5)$. The sample was nearly evenly split across freshmen, sophomores, juniors, and seniors; though an additional $5.2 \%$ were in their fifth year of schooling or higher; the OCSLS sample contained a greater percentage of freshmen (35.2\%). In the analytic sample, $47.4 \%$ of students lived on campus, compared to over half $(55 \%)$ in the OCSLS sample. More students in the analytic sample reported no religious affiliation (43\%). Age at first vaginal intercourse was similar in both samples: $16.89(S D=1.5)$ in the OCSLS sample versus 16.6 years $(S D=1.65)$ in the analytic sample.

Roughly $32 \%$ of students reported condomless vaginal sex during their last hookup. About 33\% of white students reported condomless vaginal sex during their last hookup, while $23.2 \%$ of Black students reported condomless vaginal sex. Similarly, nearly $34 \%$ of female students reported condomless vaginal sex during their last hookup while $28.1 \%$ of male students reported condomless vaginal sex. When broken down into racial and gender student groups, $25.6 \%$ of Black women reported condomless vaginal sex while $34.5 \%$ of White women reported the same. Also, 19.2\% of Black men reported condomless vaginal sex compared to $29 \%$ of White men. 
Table 2. Significant bivariate associations between independent variables and control variables.

\begin{tabular}{lrrr}
\hline Variables & $\chi^{2}$ & Degrees of Freedom & $p$ \\
\hline Race & & & \\
$\quad$ Age at first vaginal intercourse & 86.19 & 11 & $<.001$ \\
$\quad$ Undergraduate classification & 21.34 & 4 & $<.001$ \\
$\quad$ Religious affiliation & 48.54 & 2 & $<.001$ \\
$\quad$ Greek & 14.83 & 1 & $<.001$ \\
$\quad$ Athlete & 17.02 & 1 & $<.001$ \\
Gender & & & \\
Age & 17.34 & 6 & .008 \\
Age at first vaginal intercourse & 39.38 & 11 & $<.001$ \\
Undergraduate classification & 16.49 & 4 & .002 \\
Greek & 15.98 & 1 & $<.001$ \\
Athlete & 78.99 & 1 & $<.001$ \\
Condom use at last vaginal hookup & & & \\
Age & 17.34 & 6 & .02 \\
Age at first vaginal intercourse & 31.86 & 11 & .001 \\
$\quad$ Undergraduate classification & 11.79 & 4 & .019 \\
Student residence & 22.22 & 4 & $<.001$ \\
\hline
\end{tabular}

Nearly $27 \%$ of students were interested in a romantic relationship with their last hookup partner prior to the hookup, while $47 \%$ were unsure and $26 \%$ did not desire a relationship. When stratified by both race and gender, $28.6 \%$ of Black women, $30.6 \%$ of White women, $14.1 \%$ of Black men, and $20.3 \%$ of White men desired a relationship with their last hookup partner. Approximately $28 \%$ of students who reported no relationship interest partook in condomless vaginal sex during their last hookup, while $30.4 \%$ of students who were unsure of their relationship intentions reported condomless vaginal sex. Of those students who reported interest in a relationship, 38.2\% engaged in condomless sex.

\section{Bivariate associations}

Chi-square analyses revealed a significant association between pre-hookup relationship intentions and condom use at last vaginal hookup $\left(\chi^{2} \quad(2)=23.41\right.$, $p<.001)$. Post hoc tests using adjusted standardized residuals found that students who were interested in a relationship with their hookup partner were more likely to report condomless vaginal sex than those who were unsure or did not want a relationship. Chisquare analyses also found a significant association between race and condom use at last vaginal hookup $\left(\chi^{2} \quad(1)=10.17, p=.001\right)$. Black students were less likely to report condomless vaginal sex during their last hookup. Another chi-square analysis found a significant association between gender and condom use at last vaginal hookup $\left(\chi^{2}(1)=11.00, p=.001\right)$. Male students were less likely to report condomless vaginal sex during their last hookup.

Furthermore, significant bivariate associations between the independent and control variables were revealed (Table 2). Race was statistically significantly associated with age at first vaginal intercourse $(p<.001)$, undergraduate classification $(p<.001)$, religious affiliation $(p<.001)$, fraternity/sorority membership $(p<.001)$, and student athlete status $(p<.001)$. Similarly, gender was significantly associated with age $(p=.008)$, age at first vaginal intercourse $(p<.001)$, undergraduate classification $(p=.002)$, fraternity/sorority membership $(p<.001)$, and student athlete status $(p<.001)$. The chi-square analyses revealed significant bivariate associations between condom use at last vaginal hookup and age $(p=.02)$, age at first vaginal intercourse $(p=.001)$, undergraduate classification $(p=.019)$, and student residence $(p<.001)$. Accordingly, religious affiliation, fraternity/sorority membership, and student athlete status were not added to the logistic regression models during multivariate analyses.

\section{Multivariate analysis}

We used a series of logistic regression models to explore the associations of pre-hookup relationship intentions, race, and gender with condomless vaginal sex at last hookup, controlling for age, age at first vaginal intercourse, undergraduate classification, and student residence. The results of these analyses are presented in Table 3.

Model 1 contained only the four control variables. According to this model, age $(p=.039)$, age at first vaginal intercourse $(p<.001)$, and student residence $(p=.001)$ were significantly associated with condomless sex during last vaginal hookup. The Hosmer and Lemeshow test of the goodness of fit indicated that the model was a good fit to the data $(p=.187)$. In Model 2, pre-hookup relationship intentions were statistically significantly associated with condom use during last vaginal sex hookup $(p<.000)$. Students who did not want a relationship with their hookup partner were $16.2 \%$ more likely to use condoms during their last vaginal hookup than students who wanted a relationship (odds ratio $[\mathrm{OR}]=1.162$; 95\% confidence intervals, CI $[1.32,1.98])$. Students who were unsure about their relationship intentions had higher odds of using condoms ( $\mathrm{OR}=1.41 ; 95 \% \mathrm{CI}$ $[1.19,1.68])$ when compared to those who wanted a relationship. Age $(p=.027)$, age at first vaginal intercourse $(p<.001)$, and student residence $(p=.009)$ remained significantly associated with condom use. The Hosmer and Lemeshow test of the goodness of fit indicated that Model 2 was a good fit to the data $(p=.197)$. 
Table 3. Logistic regression results for condom use during last vaginal hookup.

\begin{tabular}{|c|c|c|c|c|}
\hline \multirow[b]{2}{*}{ Independent Variables } & \multirow[b]{2}{*}{ Model $1 \operatorname{Exp}(B)^{\mathrm{a}}(\mathrm{SE})^{\mathrm{b}}$} & \multicolumn{2}{|c|}{ Analytic sample $(N=3,315)$} & \multirow[b]{2}{*}{ Model $4 \operatorname{Exp}(B)^{a}(S E)^{b}$} \\
\hline & & Model $2 \operatorname{Exp}(B)^{\mathrm{a}}(\mathrm{SE})^{\mathrm{b}}$ & Model $3 \operatorname{Exp}(B)^{a}(S E)^{b}$ & \\
\hline \multicolumn{5}{|l|}{ Pre-hookup relationship intentions } \\
\hline Yes & & Ref. & Ref. & Ref. \\
\hline No & & $1.615(.104)^{* * *}$ & $1.522(.106)^{* * *}$ & $1.532(.105)^{* * *}$ \\
\hline Unsure & & $1.412(.089) * * *$ & $1.388(.090) * * *$ & $1.403(.090)^{* * *}$ \\
\hline \multicolumn{5}{|l|}{ Race } \\
\hline Black & & & Ref. & Ref. \\
\hline White & & & $.584(.154)^{* * *}$ & $.594(.153)^{* *}$ \\
\hline \multicolumn{5}{|l|}{ Gender } \\
\hline Women & & & Ref. & Ref. \\
\hline Men & & & $1.266(.084)^{* *}$ & $1.253(.083)^{* *}$ \\
\hline \multicolumn{5}{|l|}{ Control variables } \\
\hline Age & $.913(.044)^{*}$ & $.916(.045)^{*}$ & $.905(.045)^{*}$ & $.923(.030)^{*}$ \\
\hline Age at first vaginal intercourse & $1.127(.023)^{* * *}$ & $1.134(.023)^{* * *}$ & $1.532(.105)^{* * *}$ & $1.142(.024)^{* * *}$ \\
\hline \multicolumn{5}{|l|}{ Undergraduate classification } \\
\hline Freshman (first year) & Ref. & Ref. & Ref. & \\
\hline Sophomore (second year) & $.828(.120)$ & $.837(.120)$ & $.803(.121)$ & \\
\hline Junior (third year) & $.940(.150)$ & $.953(.151)$ & $.960(.152)$ & \\
\hline Senior (fourth year) & .919 (.177) & $.921(.178)$ & $.931(.179)$ & \\
\hline Fifth year and higher & $1.303(.259)$ & $1.288(.261)$ & $1.269(.263)$ & \\
\hline \multicolumn{5}{|l|}{ Student residence } \\
\hline On-campus & Ref. & Ref. & Ref. & Ref. \\
\hline Off-campus & $.944(.099)$ & $.930(.100)$ & $.956(.100)$ & $.935(.095)$ \\
\hline Parents & $.639(.131)^{* *}$ & $.641(.132)^{* *}$ & $.656(.133)^{* *}$ & $.648(.131)^{* *}$ \\
\hline Other residence & $1.256(.460)$ & $1.175(.461)$ & $1.245(.465)$ & $1.197(.463)$ \\
\hline Hosmer and Lemeshow Test (Goodness of Fit) & .187 & .197 & .931 & .190 \\
\hline
\end{tabular}

Abbreviation: Ref., reference group.

adds ratio.

${ }^{\mathrm{b}} \mathrm{Standard}$ error.

${ }^{*} p<.05 ; * * p<.01 ; * * * p<.001$.

In Model 3, both race $(p<.001)$ and gender $(p=.005)$ were found to be statistically significantly associated with condom use at last vaginal hookup. White students were less likely than Black students to use condoms during their last vaginal sex hookup $(\mathrm{OR}=.584 ; 95 \%$ CI $[.433, .790])$. Men were more likely than women to use condoms during their last vaginal sex hookup (OR $=1.26 ; 95 \%$ CI $[1.08,1.49]$ ). Age, age at first vaginal intercourse, student residence, and pre-hookup relationship intentions remained significant. The Hosmer and Lemeshow test of the goodness of fit indicated that Model 3 was a good fit to the data $(p=.931)$; the addition of race and gender greatly improved the model fit.

Another model (not shown) examined all two-way interactions among the independent variables (race$\times$ gender; race $\times$ pre-hookup relationship intentions; gender $\times$ pre-hookup relationship intentions). None of the interaction terms was found to be significant; thus, the interaction terms were excluded from the final model. In the final model, all variables with $p$ values higher than .05 were removed. The following variables were retained in the model: pre-hookup relationship intentions, race, gender, age, age at first vaginal intercourse, and student residence (Table 3). The Hosmer and Lemeshow test of the goodness of fit indicated that the model remained a good fit to the data $(p=.190)$.

\section{Comment}

The purpose of this study was to explore the association between pre-hookup relationship intentions and condomless sex during last vaginal sex hookup. The secondary purpose of this study was to investigate the association between race and gender and condom use during last vaginal sex hookup. The final model revealed that pre-hookup relationship intentions were significantly associated with condomless sex during last vaginal hookup, suggesting that students who did not want a relationship and students who were unsure of their relationship intentions were more likely to use condoms during their last vaginal hookup compared to those who desired a relationship. Further, race and gender were significantly associated with condom use. White students were less likely to have used condoms during their last vaginal hookup when compared to Black students. Male students were more likely than female students to use condoms during their last vaginal sex hookup.

Pre-hookup relationship intention is an area that deserves more examination given the strong 
association with condomless sex at last vaginal hookup. This finding lends credence to prior research that suggest hookups may be a step in relationship formation for some college students. ${ }^{18,21,33}$ It also adds complexity to the current conceptualizations of hookups as commitment-free sexual encounters between individuals seeking sexual pleasure and nothing more. These results do suggest that those seeking a relationship with their hookup partners may be at higher risk for STIs and HIV than those who desire casual partnerships. Within the context of hookups, condomless sex may be a display of trust and desire to please one's partner in hopes of securing a romantic relationship. Some hookup encounters certainly evolve into romantic relationships; however, this may not be the mutual expectation or desired outcome in many hookup partnerships. ${ }^{1,3,54}$ Competing romantic and sexual interests could render students seeking relationships more susceptible to STIs.

The results from this study are also consistent with previous findings which suggest Black students and male students were more likely to report condom use during last intercourse than White students and female students. ${ }^{41}$ While Black students exhibited greater condom use, their disproportionate representation in the STI epidemic cannot be ignored. Black students are still at greater risk for STIs despite similar or higher rates of condom use than their white counterparts. Buhi et al. ${ }^{41}$ reported that Black students were more likely than their white peers to report an STI in the past year. Similarly, $\mathrm{Hou}^{55}$ found that Black HBCU students were 4.4 times more likely to have had an STI in comparison to their White peers at predominantly White universities despite similar rates of condom use. In this study, STI histories of students were not collected, which limits the ability to assess racial differences in STI risks. Future studies should investigate such histories to gauge the sexual risks posed by hookup participation.

The findings regarding gender are reflective of the current literature which details lower rates of condom use among college women. Several factors not addressed in this study may contribute to these lower rates of condom use. Studies of college women have shown condom use tends to decline overtime as partners become more familiar and hormonal contraceptive use increases. ${ }^{21,56}$ On average, students in this study reported having more hookup partners with whom they were familiar since starting college compared to hookup partners who were strangers. Since hookups are not necessarily one-time sexual encounters, it possible condom use declines with each subsequent hookup with a familiar partner. Future research should examine differences in condom use with familiar hookup partners versus those who are strangers.

Another factor could be gender ratio disparities. It is theorized that the overabundance of women on college campuses influence the sexual decision making of college women as there is increased competition for suitable male partners. ${ }^{22,23,28,30,33}$ Some women may feel condom negotiation and discussion of safer sex threatens their status in the sexual marketplace. ${ }^{32,34}$ Corroborating this, Foreman ${ }^{21}$ found that women seeking romantic relationships were willing to use condoms as a bargaining tools in order to fulfill their relationship desires. More attention is needed in this area to understand how these social and interpersonal factors influence the sexual decision-making and behaviors of college women.

The interactions among pre-hookup relationship intentions, race, and gender were found to be insignificant in this study. However, this finding does not provide definitive evidence of no difference in relationship intentions and condom use among the student groups when stratified by both race and gender. When stratified by race and gender, $28.6 \%$ of Black women, $30.6 \%$ of White women, $14.1 \%$ of Black men, and $20.3 \%$ of White men desired a relationship with their last hookup partner. Further, $25.6 \%$ of Black women reported condomless vaginal sex during their last hookup while $34.5 \%$ of White women reported the same. Also, 19.2\% of Black men reported condomless vaginal sex during their last hookup compared to $29 \%$ of White men. Accordingly, the insignificant interaction terms may be reflective of the small number of Black men $(n=99)$ and women $(n=168)$ in the analytic sample. A larger sample of Black students is needed to explore the intersections between prehookup relationship intentions, race, and gender and their possible association with condom use during vaginal hookups.

Understanding gender and racial differences in condom use during hookups help elucidate the potential risks posed by casual sexual practices and provides guidance for how and for whom to intervene. Per the theory of Intersectionality, race and gender are multidimensional and intersecting social categories that operate at the micro-level of the individual and reflect systems of privilege and oppression at the macro level which produce and maintain social disparities. ${ }^{33,57,58}$ Much of the hookup literature treats race and gender as independent categories of analysis without attention to the impact multiple marginalized identities may 
have on students' sexual behavior and risk factors. It is clear both race and gender influence sexual risk as young women and young Black adults are disproportionately impacted by chlamydia and gonorrhea. Also, there is evidence of gender and racial differences in condom use. However, this study did not reveal a significant three-way interaction among race and gender and condom use. This insignificant finding was possibly due to the small number of Black students and the exclusion HBCUs in the OCSLS. It is possible that the unique sociocultural setting of HBCU campuses where Black students are the majority - could influence Black students' sexual behaviors and decision making. ${ }^{41,59}$

Considering this, intersectional research on differences in condom use among Black and White collegiate men and women is needed. For example, young Black women bear the status of being both Black and female and are currently overrepresented in the STI epidemic. Behind gay, bisexual men, and other men who have sex with men (MSM), Black women surpass all racial and gender groups in the rate of reported chlamydia and gonorrhea cases. ${ }^{9}$ Further, studies suggest that Black college women report lower condom use than Black college men. ${ }^{44,45}$ Considering these findings, it is imperative to consider the intersecting relationship of race and gender when examining differences in condom use.

\section{Strengths and limitations}

This exploratory study has several notable strengths. First, this study used data from a large, national albeit not nationally representative - sample of students. To our knowledge, the OCSLS is the largest and most comprehensive survey of college students' hookup attitudes and behaviors. Second, this research fills a critical gap in the hookup literature by examining racial and gender differences in condom use during hookups. The study also went deeper to examine the intersection of race and gender and the possible multiplicative these social categories have on condom use during vaginal hookups. Finally, the study addresses the relationship between pre-hookup relationship intentions and condom use at last vaginal hookup. Pre-hookup relationship intentions did not moderate the relationship between race, gender, and condom use; however, the findings suggest students who desire relationships with their hookup partners may be at greater risk for STIs due to decreased condom use.

The study was not without its limitations. One limitation of the study is the small number of Black students - all from predominantly white institutions in the analytic sample. A larger sample which includes students from HBCUs could have provided more reliable estimates of Black student's condom use. Further, the analyses of the interaction term could have could have yielded different results if a larger, more diverse sample of Black students was utilized. Another limitation is that prior hookups with the same partner were not controlled for. Some students could have had a history of multiple hookups with the same partner over a period of time. Additionally, there was no differentiation between familiar hookup partners and those who were strangers. Accounting for such factors could possibly explain differences in condom use. Another limitation is the lack of student STI history. Although racial and gender differences in condom use were revealed, no inferences can be made regarding STI disparities among those who participate in condomless hookups. Finally, this sample was limited to heterosexual students. Gay, lesbian, and bisexual students accounted for $6 \%$ of the total OCSLS sample population. The sexual practices and behaviors of other marginalized group within hookup culture deserves closer examination in future work.

\section{Conclusion}

Despite its limitations, the study highlights the need to reexamine current generalizations surrounding hookup culture, its associated sexual behaviors and differential risks posed to students embodying marginalized identities. Accordingly, the findings have clear implications for college health professionals and researchers. Tailored programs and interventions that not only acknowledge and address racial and gender differences in sexual health outcomes, but also disparate outcomes for students embodying multiple marginalized identities are needed.

Also, the results presented challenge current conceptualizations of hookups as being brief, commitment-free sexual encounters. It is possible that hookups may serve as means to an end for students seeking long-term, romantic relationships with their hookup partners. In turn, this practice could render these students more susceptible to STIs - particularly Black and female students. Future college health research could delve deeper into the role of hookups in the formation of romantic relationships among college students in order to unpack the factors underlying the significant association found between prehookup relationship intentions and condom use at last vaginal hookup. 
In conclusion, relationship intentions and the intersecting relationship of race and gender are often overlooked in hookup literature and broader collegiate sexual health programing. Yet, evidence suggests these factors may influence condom use and STI risk, particularly among marginalized populations. Targeted collegiate sexual health programing that addresses the complexities of relationship formation, race, and gender and their influence on healthy sexual decision making is needed. College health professionals play an important role in acknowledging the hookup practices of diverse students and developing appropriate, culturally and socially competent STI risk reduction programing and interventions.

\section{Conflict of interest disclosure}

The authors have no conflicts of interest to report.

\section{References}

1. Garcia JR, Reiber C, Massey SG, Merriwether AM. Sexual hookup culture: a review. Rev Gen Psychol. 2012;16(2):161-176.

2. Bogle KA. Hooking up: Sex, Dating, and Relationships on Campus. New York: New York University Press; 2008.

3. Heldman C, Wade L. Hook-up culture: setting a new research agenda. Sex Res Soc Policy. 2010;7(4): 323-333.

4. Stinson RD. Hooking up in young adulthood: a review of factors influencing the sexual behavior of college students. J College Stud Psychother. 2010;24(2): 98-115. doi:10.1080/87568220903558596.

5. Eshbaugh EM, Gute G. Hookups and sexual regret among college women. J Soc Psychol. 2008;148(1): 77-89.

6. Fielder RL, Carey MP. Predictors and consequences of sexual "hookups" among college students: a shortterm prospective study. Arch Sex Behav. 2010;39(5): 1105-1119. doi:10.1007/s10508-008-9448-4.

7. Lambert TA, Kahn AS, Apple KJ. Pluralistic ignorance and hooking up. J Sex Res. 2003;40(2):129.

8. Paul EL, McManus B, Hayes A. Hookups": characteristics and correlates of college students' spontaneous and anonymous sexual experiences. J Sex Res. 2000; 37(1):76-88.

9. Centers for Disease Control and Prevention. Sexually Transmitted Disease Surveillance 2015. Atlanta, GA: U. S. Department of Health and Human Services; 2016.

10. Lewis MA, Granato H, Blayney J, Lostutter T, Kilmer J. Predictors of hooking up sexual behaviors and emotional reactions among U.S. college students. Arch Sex Behav. 2012;41(5):1219-1229. doi:10.1007/s10508-0119817-2.

11. Fielder RL, Carey MP. Prevalence and characteristics of sexual hookups among first-semester female college students. J Sex Marital Ther. 2010;36(4):346-359. doi: 10.1080/0092623X.2010.488118.

12. American College Health Association. American College Health Association-National College Health Assessment II: Undergraduate Student Reference Group Data Report Spring 2016. Hanover, MD; 2016.

13. Bearak JM. Casual contraception in casual sex: lifecycle change in undergraduates' sexual behavior in hookups. Soc Forces. 2014;93(2):483-513. doi:10.1093/ sf/sou091.

14. Downing-Matibag TM, Geisinger B. Hooking up and sexual risk taking among college students: a health belief model perspective. Qual Health Res. 2009;19(9): 1196-1209.

15. Dworkin J. Risk taking as developmentally appropriate experimentation for college students. J Adolesc Res.2005; 20(2):219-241. doi:10.1177/0743558404273073.

16. Hood KB, Shook NJ. Who cares what others think? The indirect effect of others' attitudes on condom use intentions. Int J Sex Heal. 2014;26(4):282-294.

17. LaBrie JW, Hummer JF, Ghaidarov TM, Lac A, Kenney SR. Hooking up in the college context: the event-level effects of alcohol use and partner familiarity on hookup behaviors and contentment. J Sex Res. 2014;51(1):62-73. doi:10.1080/00224499.2012.714010.

18. Garcia JR, Reiber C. Hook-up behavior: a biopsychosocial perspective. J Soc Evol Cult Psychol. 2008;2(4): 192-208.

19. Owen J, Fincham FD. Young adults' emotional reactions after hooking up encounters. Arch Sex Behav. 2011;40(2):321-330. doi:10.1007/s10508-010-9652-x.

20. Foreman FE. African American college women: constructing a hierarchy of sexual arrangements. AIDS Care. 2003;15(4):493-504.

21. Foreman FE. Intimate risk: sexual risk behavior among African American college women. J Black Stud. 2003;33(5):637-653.

22. Ferguson YO, Quinn SC, Eng E, Sandelowski M. The gender ratio imbalance and its relationship to risk of HIV/AIDS among African American women at historically black colleges and universities. AIDS Care. 2006;18(4):323-331. doi:10.1080/09540120500162122.

23. Alleyne B, Gaston G. Gender disparity and HIV risk among young black women in college: a literature review. Affil J Women Soc Work. 2010;25(2):135-145. doi:10.1177/0886109910364348.

24. Snyder TD, Dillow SA. Digest of Education Statistics 2013. Washington, DC: National Center for Education Statistics, Institute of Education Sciences, U.S. Department of Education; 2015.

25. Ellingson S, Laumann EO, Paik A, Mahay J. The theory of sexual markets. In: Laumann EO, Ellingson S, Mahay J, Paik A, Youm Y, eds. The Sexual Organization of the City. Chicago: University of Chicago Press; 2004:3-38.

26. Kelly C. Feminist ethics evaluating the hookup culture. J Fem Stud Relig (Indiana Univ Press 2012;28(2): 27-48.

27. Rhoads S. Hookup culture: the high costs of a low "price" for sex. Society. 2012;49(6):515-519.

28. Uecker JE, Regnerus MD. Bare market: campus sex ratios, romantic relationships, and sexual behavior. 
Sociol Q. 2010;51(3):408-435. doi:10.1111/j.15338525.2010.01177.x.

29. Bradshaw C, Kahn A, Saville B. To hook up or date: which gender benefits? Sex Roles. 2010;62(9-10): 661-669. doi:10.1007/s11199-010-9765-7.

30. Adkins T, England P, Risman BJ, Ford J. Student bodies: does the sex ratio matter for hooking up and having sex at college? Soc Curr. 2015;2(2):144-162.

31. Guttentag M, Secord PF. Too Many Women? The Sex Ratio Question. Beverly Hills: Sage Publications; 1983.

32. Hall NM, Lee AK, Witherspoon DD. Factors influencing dating experiences among African American emerging adults. Emerg Adulthood. 2014;2(3):184-194. doi:10.1177/2167696813520154.

33. Jenkins Hall W, Tanner AE. US Black college women's sexual health in hookup culture: intersections of race and gender. Cult Heal Sex 2016;18(11):1058. doi: 10.1080/13691058.2016.1183046.

34. Newsome VR, Airhihenbuwa CO, Snipes SA. Educated and at-risk: how the shortage of available partners influences disparities in HIV risk for collegeeducated African-American women. J Heal Disparities Res Pract. 2014;7(Suppl. 2):47-65.

35. Owen J, Rhoades G, Stanley S, Fincham F. Hooking up among college students: demographic and psychosocial correlates. Arch Sex Behav. 2010;39(3):653-663. doi:10.1007/s10508-008-9414-1.

36. Dworkin SL. Who is epidemiologically fathomable in the HIV/AIDS epidemic? Gender, sexuality, and intersectionality in public health. Cult Health Sex. 2005; 7(6):615-623.

37. McCree DH, Rompalo A. Biological and behavioral risk factors associated with STDs/HIV in women: Implications for behavioral intervention. In: Aral SO, Douglass, Jr., JM, Lipshutz JA, eds. Behavioral Interventions for Prevention and Control of Sexually Transmitted Diseases. New York, NY: Springer; 2007: 310-324.

38. Moench TR, Chipato T, Padian NS. Preventing disease by protecting the cervix: the unexplored promise of internal vaginal barrier devices. AIDS. 2001;15(13): 1595-1602. doi:10.1097/00002030-200109070-00001.

39. Asare M. Using the theory of planned behavior to determine the condom use behavior among college students. Am J Health Stud. 2015;30(1):43-50.

40. Walsh JL, Fielder RL, Carey KB, Carey MP. Changes in women's condom use over the first year of college. $J \quad$ Sex Res. 2013;50(2):128-138. doi:10.1080/ 00224499.2011 .642024$.

41. Buhi ER, Marhefka SL, Hoban MT. The state of the union: sexual health disparities in a national sample of US college students. J Am Coll Heal. 2010;58(4): 337-346. doi:10.1080/07448480903501780.

42. Davis C, Sloan M, MacMaster S, Kilbourne B. HIV/ AIDS knowledge and sexual activity: an examination of racial differences in a college sample. Health Soc Work. 2007;32(3):211-218.

43. Thomas PE, Voetsch AC, Song B. HIV risk behaviors and testing history in historically black college and university settings. Public Health Rep. 2008;123(Suppl 3):115-125.
44. Hodge M, Wade BH. HIV/AIDS perceptions, attitudes and behaviors among HBCU students. Challenge. 2007;13(2):13-36.

45. El Bcheraoui C, Sutton MY, Hardnett FP, Jones SB. Patterns of condom use among students at historically Black colleges and universities: implications for HIV prevention efforts among college-age young adults. AIDS Care. 2013;25(2):186-193. doi:10.1080/ 09540121.2012 .687864$.

46. Armstrong EA, England P, Fogarty ACK. Accounting for women's orgasm and sexual enjoyment in college hookups and relationships. Am Sociol Rev. 2012;77(3): 435-462. doi:10.1177/0003122412445802.

47. Reece M, Herbenick D, Schick V, Sanders SA, Dodge $\mathrm{B}$, Fortenberry JD. Condom use rates in a national probability sample of males and females ages 14 to 94 in the United States. J Sex Med. 2010;7:266-276.

48. O’Donnell L, O’Donnell CR, Stueve A. Early sexual initiation and subsequent sex-related risks among urban minority youth: the reach for health study. Fam Plann Perspect. 2001;33(6):268.

49. Burdette AM, Ellison CG, Hill TD, Glenn ND. Hooking up at college: does religion make a difference? J Sci Study Relig. 2009;48(3):535-551. doi: 10.1111/j.1468-5906.2009.01464.x.

50. Brimeyer TM, Smith WL. Religion, race, social class, and gender differences in dating and hooking up among college students. Sociol Spectr. 2012;32(5): 462-473. doi:10.1080/02732173.2012.694799.

51. Scott-Sheldon LAJ, Carey KB, Carey MP. Health behavior and college students: does Greek affiliation matter? J Behav Med. 2008;31(1):61-70.

52. Reel JJ, Joy E, Hellstrom EM. Reducing high-risk sexual behaviors among college athletes. J Sport Psychol Action. 2012;3(1):21-29. doi:10.1080/21520704.2011.649193.

53. Willoughby BJ, Carroll JS. The impact of living in coed resident halls on risk-taking among college students. J Am Coll Health. 2009;58(3):241-246.

54. Paik A. Hookups, dating, and relationship quality: does the type of sexual involvement matter? Soc Sci Res. 2010;39(5):739-753. doi:10.1016/j.ssresearch.2010.03.011.

55. Hou S-I. HIV-related behaviors among black students attending Historically Black Colleges and Universities (HBCUs) versus white students attending a traditionally white institution (TWI). AIDS Care. 2009;21(8): 1050-1057. doi:10.1080/09540120802626196.

56. Manning WD, Longmore MA, Giordano PC. The relationship context of contraceptive use at first intercourse. Fam Plann Perspect. 2000;32(3):104-110.

57. Bowleg L. The problem with the phrase women and minorities: intersectionality an important theoretical framework for public health. Am J Public Health. 2012; 102(7):1267-1273. doi:10.2105/AJPH.2012.300750.

58. Crenshaw K. Demarginalizing the intersection of race and sex: a black feminist critique of antidiscrimination doctrine, feminist theory and antiracist politics. Univ Chic Leg Forum. 1989;1989:139-167.

59. Younge SN, Corneille MA, Lyde M, Cannady J. The paradox of risk: historically black college/university students and sexual health. J Am Coll Heal. 2013; 61(5):254-262. doi:10.1080/07448481.2013.799480. 